\title{
MEGAMINERÍA EN MÉXICO ¿UN CAMINO HACIA EL DESARROLLO LOCAL Y NACIONAL?
}

\section{Darcy Tetreault*}

RESUMen: La nueva Ley Federal de Derechos incluye mecanismos para incrementar los impuestos sobre la actividad minera en México y canalizar esos recursos al financiamiento de proyectos de desarrollo social en las regiones mineras del país. En este artículo se analiza la reforma en el contexto de las políticas neoliberales que han imperado en el sector desde principios de los años noventa del siglo xx. El argumento es que la reforma resulta limitada en tanto da por sentadas la deseabilidad y la prioridad de los grandes proyectos de minería, evadiendo así el derecho de las comunidades afectadas de rechazarlos para seguir un camino alternativo hacia el desarrollo local. La viabilidad de las alternativas asociadas a los movimientos de resistencia a la megaminería se ilustra con el caso de Capulálpam, una comunidad zapoteca en la Sierra Juárez del estado de Oaxaca.

palabras Clave: minería, conflictos socioambientales, Ley Federal de Derechos, Capulálpam, México.

\footnotetext{
* Docente-investigador de la Unidad Académica de Estudios del Desarrollo de la Universidad Autónoma de Zacatecas, México.
} 
ABSTRACT: The new Federal Law of Rights includes mechanisms to increase taxes on mining activities in Mexico and to channel the resources derived from these taxes towards financing social development projects in the country's mining regions. This reform is analyzed in the context of the neoliberal policies that have reigned in the sector since the beginning of the 1990s. It is argued that the reform is limited insofar as it takes for granted the desirability and priority of large mining projects, evading the right of affected communities to reject these projects in order to pursue alternative paths towards local development. The viability of the alternatives associated with resistance movements to mega-mining are illustrated by the case of Capulálpam, a Zapotec community in the Sierra Juárez in the state of Oaxaca.

KEYWORDS: mining, social environmental conflicts, Federal Law of Rights, Capulálpam, México. 


\section{INTRODUCCIÓN}

$\mathrm{P}$ ublicada el 11 de diciembre de 2013 en el Diario Oficial de la Federación, la Ley Federal de Derechos (LFD) incluye mecanismos para cobrar nuevos impuestos a las empresas mineras en México y para canalizar esos recursos fiscales al financiamiento de proyectos sociales en las regiones mineras del país. De esta manera, mientras que el gobierno de Enrique Peña Nieto abre el sector energético a la inversión privada y extranjera, en el sector minero toma un paso moderado hacia cuando menos uno de los preceptos del «nuevo extractivismo» practicado en diversas formas por los países sudamericanos con gobiernos "progresistas» de Argentina, Brasil, Uruguay, Bolivia, Ecuador y Venezuela (Gudynas, 2010). Básicamente, significa un nuevo acuerdo entre el Estado y el capital donde el primero retiene una mayor proporción de la renta con la pretensión de usarla para financiar proyectos de desarrollo social.

En este texto se contextualizan los recientes cambios hechos a la LFD en una revisión de las políticas neoliberales que han imperado en el sector minero mexicano desde principios de los años noventa. Como se verá, si bien la receta neoliberal ha conllevado crecientes niveles de inversión y producción en el sector, lo cierto es que los beneficios para la población local y nacional, en general, han sido mínimos; mientras que los costos recaen brutalmente sobre las comunidades rurales afectadas por las «externalidades ambientales» de la megaminería tóxica.

Los cambios hechos a la LFD tienen el objetivo de revertir parcialmente la mala distribución de los costos y beneficios históricamente asociada con el sector minero. Sin embargo, los cambios están en extremo limitados debido a que dan por sentadas la deseabilidad y la prioridad de los grandes proyectos de minería, evadiendo así el derecho de las comunidades afectadas de rechazarlos para seguir un camino alternativo hacia el desarrollo local, el cual pretende ser mucho más armonioso con la Madre Tierra.

Para desarrollar este argumento, este artículo empieza con un breve resumen de las políticas neoliberales aplicadas al sector minero mexi- 
cano. De allí, pasa a una descripción general de las afectaciones ambientales y sociales de la megaminería tóxica. La siguiente sección esboza la reforma en materia minera incorporada a la LFD, señalando sus limitaciones. En la penúltima sección se ilustra la viabilidad de algunas de las alternativas asociadas a los movimientos de resistencia con el ejemplo de Capulálpam, una comunidad zapoteca en la Sierra Juárez del estado de Oaxaca. El texto termina con una serie de reflexiones políticas y éticas sobre la megaminería tóxica.

\section{ANTECEDENTES Y POLÍTICAS NEOLIBERALES}

A diferencia del sector petrolero, el sector minero en México nunca fue nacionalizado. No obstante, después de la Revolución y sobre todo durante los años sesenta y setenta, se instrumentaron políticas públicas con el objetivo de «mexicanizar» el sector para que el Estado ejerciera más control en la producción y el beneficio de los metales y minerales considerados estratégicos para alimentar el proceso de industrialización. En esta línea, la Ley Minera de 1961 estableció que todas las compañías mineras en México deberían tener, por lo menos, 51 por ciento de capital mexicano. En 1976 se hicieron otras modificaciones a esa Ley para fortalecer la participación del Estado, relevando la producción de hierro, cobre, carbón y azufre.

Por cierto, durante los años setenta y ochenta la producción paraestatal no puso fin a la transferencia de la renta minera al sector privado. Emergieron nuevas formas de dependencia financiera, comercial y tecnológica (Delgado Wise y Del Pozo, 2002; Sariego et al., 1988), y la falta de regulación ambiental eficaz dio lugar a diversas formas de degradación ambiental (Coll et al., 2002). Además, durante el periodo del "desarrollismo» los campesinos e indígenas fueron desposeídos de sus tierras y recursos naturales, al igual que hoy, para dar paso a los grandes proyectos mineros. La experiencia de los nahuas en la Sierra de Manantlán es ilustrativa (Tetreault, 2013). 
Desde una perspectiva laboral, si bien los mineros sindicalizados disfrutaron en los años setenta de mayores ingresos en términos reales y su sindicato tenía más poder político, lo cierto es que el Sindicato Nacional de Trabajadores Mineros, Metalúrgicos y Similares de la República Mexicana (sNтmmsrm) era subordinado a los imperativos del Ejecutivo federal, formando parte del sistema político corporativista y clientelista del Partido Revolucionario Institucional (PRI) (Sariego et al., 1988). Por otra parte, la toma de decisiones del sntmmsrm fue centralizada en el Comité Ejecutivo General (ibid.), dirigido durante 40 años (1960-2000) por el mismo secretario, Napoleón Gómez Sada.

Las reformas neoliberales se aplicaron en tres etapas: primera, durante la presidencia de Miguel de la Madrid (1982-1988) el gobierno federal introdujo diversos incentivos fiscales para fomentar la inversión privada; eliminó impuestos a la exportación de metales y minerales, y redujo aranceles para la importación de maquinaria y equipo minero. Además, en el contexto de la crisis de la deuda, el cierre de minas y de plantas de beneficio se tradujo en la pérdida de miles de trabajos (Burnes, 2006), mientras que altas tasas de inflación disminuyeron el valor real de los salarios.

La segunda etapa coincide con la primera mitad del sexenio de Carlos Salinas (1988-1994). Su gobierno privatizó las compañías mineras paraestatales, las plantas de beneficio y las reservas públicas de minerales, vendiéndolos a precios muy por debajo de su valor en el mercado y con poca transparencia (Delgado Wise y Del Pozo, 2002). Los principales beneficiarios de este proceso de privatización incluían a Jorge Larrea, dueño de Grupo México; Alberto Bailleres, de Industrias Peñoles; y Carlos Slim, cuyo vasto imperio incluye la Minera Frisco. Donde hubo resistencia de los mineros sindicalizados, como por ejemplo en Cananea, el gobierno recurrió a la represión para romper la huelga, además de declarar en bancarrota la empresa paraestatal para facilitar su privatización (Sariego, 2009).

La tercer etapa inicia a partir de 1992, cuando el gobierno de Salinas hizo cambios a la Ley Minera para abrir el sector por completo a la 
inversión extranjera directa (IED), además de ampliar el plazo de las concesiones de 25 a 50 años, prorrogables por otros 50. En el mismo año, Salinas modificó el artículo 27 de la Constitución y la Ley Agraria para facilitar la compra y venta de tierras ejidales y comunales. Para no dejar lugar a dudas, el notorio artículo 6 de la Ley Minera consta que »la exploración, explotación y beneficio de los minerales serán preferentes sobre cualquier otro uso o aprovechamiento del terreno».

Con todo, la estrategia neoliberal se orienta a crear un ambiente amigable para las inversiones privadas, con ventajas comparativas para atraer el capital trasnacional en una economía mundial globalizada y competitiva que permite el libre flujo de capital y mercancías. Para seducir las inversiones de compañías mineras nacionales y trasnacionales, las reformas estructurales en México se diseñaron para crear mercados para la tierra, el agua y los recursos subterráneos; remover restricciones sobre las inversiones extranjeras, brindar seguridad sobre los derechos de propiedad privada, simplificar los trámites administrativos y cobrar de las compañías mineras una carga tributaria leve.

En este esquema, las leyes ambientales también son subordinadas al imperativo de acomodar los intereses del gran capital. En México las políticas ambientales fueron fortalecidas (sobre el papel) a partir de finales de los años ochenta, de acuerdo con los preceptos neoliberales del «modelo dominante de desarrollo sustentable». ${ }^{1}$ Paralelamente, se construyó un entramado de agencias gubernamentales ambientales en los tres niveles de gobierno, con la Secretaría de Medio Ambiente y Recursos Naturales (Semarnat) en la cúpula. No obstante, este desarrollo institucional, como hemos visto en numerosos conflictos socioambientales en torno a la minería a lo largo del país (Tetreault, 2014), cuando está en juego mucho dinero, las leyes ambientales de México se esquivan para acomodar los intereses del gran capital. Quizás el caso

${ }^{1}$ Para un análisis comparativo del modelo dominante de desarrollo sustentable con otras escuelas de pensamiento ecológico en las ciencias sociales, véase Tetreault (2008). 
más notorio sea el de la mina de San Xavier, de la compañía canadiense New Gold, en el estado de San Luis Potosí. ${ }^{2}$

El caso más reciente es el derrame de 40 millones de metros cúbicos de sulfato de cobre en el río Sonora, debido a la negligencia de Grupo México, que estaba depositando jales tóxicos en una presa todavía de baja construcción, sin piletas de contención u otras medidas de contingencia especificadas en la Norma Oficial Mexicana (NOM) que establece los requisitos de protección ambiental para los sistemas de lixiviación de cobre (NOM-159-semarnat-2011). A pesar de que el titular de la Semarnat, Juan José Guerra Abud, consideró que fue el peor accidente en la historia de la industria minera en México, no se aplicó el artículo 72 de la Ley General del Equilibrio Ecológico y la Protección al Ambiente (LGEEPA) según el cual:

cuando la gravedad de la infracción lo amerite, la autoridad, solicitará a quien los hubiere otorgado, la suspensión, revocación o cancelación de la concesión, permiso, licencia y en general de toda autorización otorgada para la realización de actividades comerciales, industriales o de servicios, o para el aprovechamiento de recursos naturales que haya dado lugar a la infracción.

En lugar de aplicar esta Ley, los altos mandos del gobierno de Peña Nieto han optado por sanciones monetarias; multas de 40 millones de pesos y hasta 2 mil millones de pesos para financiar los trabajos de saneamiento y la indemnización a la población afectada. En total, estas "sanciones ejemplares» representan menos de una tercera parte de las ganancias netas de Grupo México durante el segundo trimestre de 2014.

En fin, la laxa aplicación de las leyes ambientales forma parte de una estrategia más amplia de crear condiciones atractivas y competitivas

\footnotetext{
${ }^{2}$ En el caso de San Xavier se construyó una megamina de oro a cielo abierto, con un sistema de lixiviación que emplea cianuro, a sólo $18 \mathrm{~km}$ de la capital del estado, San Luis Potosí. A pesar de la orden judicial de cerrar la mina, la explotación y la concomitante destrucción han seguido adelante sin interrupción, evidenciando la complicidad de múltiples actores gubernamentales, incluso de la Semarnat.
} 
para las inversiones privadas, bajo el supuesto de que éstas se traduzcan en la creación de empleos y en otros derrames económicos positivos. De la misma manera, las políticas laborales vigentes están diseñadas para «flexibilizar» la fuerza de trabajo y ejercer presión a la baja sobre los salarios, nuevamente para atraer la IED. Adicionalmente, en numerosas huelgas desde los años noventa, los mineros han sido desalojados de manera violenta; los líderes sindicales han sido perseguidos, incluso Napoleón Gómez Urrutia, quien tomó de su padre las riendas del SNTMMSRM en 2000, cuando se puso enfermo; y los mineros sindicalizados han sido divididos, con la ayuda del gobierno federal en tanto este mismo ha tolerado la formación de sindicatos «blancos» que quedan bajo el control de los directivos de las empresas mineras. A fin de cuentas, lo anterior ayuda a dar confianza al capital minero que considere hacer inversiones en el país.

Por cierto, la estrategia neoliberal ha sido exitosa en sus propios objetivos estrechos de atraer inversiones privadas e incrementar la producción de minerales y metales. La IED ha crecido en México con grandes pasos desde mediados de los años noventa, alcanzando un promedio de 568.7 millones de dólares anuales entre 2005 y 2011. ${ }^{3}$ Hoy en día, México comparte con Chile el primer lugar en América Latina en atracción de IED para la exploración minera, y el cuarto lugar en escala mundial, después de Canadá, Australia y Estados Unidos. Por otra parte, aunque la IED en el sector minero ha crecido drásticamente desde los años noventa, ésta sigue siendo eclipsada por las inversiones de compañías mexicanas. Entre 2005 y 2011, las inversiones hechas por las empresas de base nacional fueron cinco veces mayores que la IED. Esto es el legado del proceso de privatización: un pequeño grupo de magnates mineros de nacionalidad mexicana que ejerce el control oligopólico sobre el sector.

En la producción de metales no ferrosos, destacan dos compañías: Grupo México (de Germán Larrea) e Industrias Peñoles (de Alberto Bailleres). El primero produjo más de dos terceras partes de cobre en

${ }^{3}$ Cálculos propios basados en datos publicados en la Secretaría de Economía (SE) (2012: 22). 
México en 2012, una quinta parte de plomo, una sexta parte de zinc y varios otros metales en menores proporciones. Industrias Peñoles produjo en el mismo año aproximadamente una tercera parte de la plata, zinc y plomo, y una quinta parte del oro. ${ }^{4}$ La Minera Frisco de Carlos Slim también produce grandes cantidades de estos metales, pero se encuentra en un distante tercer lugar.

El sector siderúrgico también exhibe características monopólicas. El Grupo Acerero del Norte (GAN) — propiedad de los mexicanos Xavier Autrey Maza y Alonso Ancira Elizondo- controla más de 90 por ciento de la producción nacional de carbón, tres cuartas partes del coque y 30 por ciento de la producción nacional de hierro. ${ }^{5}$ El resto de la producción de hierro en México se produce por Ternium y ArcelorMittal, de capital argentino-italiano e indio, respectivamente.

Dichos empresarios mexicanos no son los únicos que están enriqueciéndose a través de las explotaciones mineras en México, los poderosos cárteles de narcotraficantes han diversificado sus actividades para incluir inter alia la extracción y comercialización de minerales. En Chihuahua, los Zetas han explotado carbón usando tiros verticales rudimentarios y peligrosos para los trabajadores, para posteriormente vender el producto a las empresas mineras mexicanas con concesiones en el mismo estado. Asimismo, en el centro occidente del país, en los estados de Michoacán, Colima y Jalisco, grupos armados tienen años extrayendo hierro con minas abiertas irregulares y transportando millones de toneladas de minerales no procesados en carreteras públicas hasta los principles puertos, donde se vende el producto a compradores chinos al margen de la ley. El decomiso de minerales ferruginosos en Manzanillo y en los buques chinos desde marzo de 2014 es sólo la punta del iceberg.

Por su parte, las empresas extranjeras van tras los metales preciosos. Desde 1990, las empresas con 100 por ciento de capital extranjero han podido participar en la arriesgada fase de exploración. En el marco del

\footnotetext{
${ }^{4}$ Cálculos propios basados en los datos publicados en Camimex (2013).

${ }^{5}$ Ibid.
} 
Tratado de Libre Comercio de América del Norte (TLCAN), las compañías mineras estadounidense y canadienses empezaron con ventaja, sobre todo los canadienses debido a las diversas formas de apoyo económico y político que han recibido del gobierno de su país, lo cual se traduce en imperialismo (Gordon, 2010; Denault y Sacher, 2012). Actualmente, de las 288 empresas mineras extranjeras registradas en el país, 208 son canadienses, y produjeron casi dos terceras partes del oro y casi la mitad de la plata extraídos del subsuelo mexicano en 2012. La minera Goldcorp es, por mucho, la empresa canadiense más poderosa en México. Por sí misma controla una cuarta parte de la producción nacional de oro y plata.

Con todo, el valor real de la producción minero-metalúrgica mexicana anual se cuadruplicó con creces entre 2000 y 2011, alcanzando su máximo nivel en 2012 con 234.1 mil millones de pesos, para posteriormente disminuir a 200.9 mil millones de pesos en 2013, debido a la caída en los precios internacionales de metales y también porque los nuevos impuestos para la minería incorporados a la LFD «inhibieron varios proyectos de exploración» (Camimex, 2014: 10-11). Hoy en día, la minería es el quinto sector de la economía mexicana en generar divisas extranjeras, después de la automotriz, la electrónica, el petróleo y las remesas (2014:9).

Si bien los precios internacionales de los metales y minerales han caído sensiblemente desde 2012, lo cierto es que siguen muy por encima de los precios de los años noventa, de tal manera que la minería todavía es altamente rentable en México, como atestiguan las ganancias netas de Grupo México durante los primeros dos trimestres de 2014: con 885 millones de dólares.

El problema con el modelo mexicano neoliberal, o más bien uno de los problemas, es que las altas ganancias realizadas por la industria minero-metalúrgica han quedado concentradas en las manos de los magnates mencionados. Aun durante el apogeo del boom minero, la industria contribuyó relativamente poco al erario. El costo de las concesiones es simbólico, no habían regalías hasta la reforma a la LFD y gracias a los 
múltiples mecanismos fiscales disponibles al gran capital para reducir sus impuestos, las empresas mineras sólo pagaron al Estado 1.2\% del valor de su producción entre 2005 y 2010 (ASF, 2012).

La creación de trabajos siempre está en el centro de los discursos que pretenden defender los intereses del gran capital minero. La Cámara Minera de México (Camimex, 2014: 10) presume que el sector minero-metalúrgica generó 333,000 empleos en México en 2013, y que estos empleos pagan en promedio 40 por ciento más que el promedio nacional. Cuando se desagregan los datos, sin embargo, se puede observar que sólo una tercera parte de estos trabajos están en las actividades de extracción y beneficio de minerales; las otras dos terceras partes se derivan de "la fabricación de productos de minerales no metálicos» y de «las industrias metálicas básicas» (SE, 2012:25). Aun si incluimos estas últimas dos categorías, la totalidad de los trabajos en el sector minerometalúrgica sólo representa 2.0 por ciento de los empleos formales en escala nacional y 0.62 por ciento de la población económicamente activa.

Lo que pasa es que la industria minera es altamente mecanizada. En términos marxistas se refleja la tendencia al aumento de la composición orgánica de capital, de tal manera que la minería genera cada vez menos trabajos en relación con el valor de la producción. Esto explica por qué en 1978, antes de la aplicación de los programas de «modernización» que acompañaron el proceso de privatización, el sector minero-metalúrgico mexicano empleó 60,000 personas más que en la actualidad. ${ }^{6}$

Históricamente, los salarios en el sector minero han estado por encima del promedio nacional, debido a la peligrosidad y lo desagradable del trabajo en las minas (Sariego et al., 1988). En efecto, se registraron 439 fatalidades por accidentes en las minas mexicanas entre 2006 y principios de $2014 .{ }^{7}$ En 2012, el salario promedio diario en las actividades mineras y metalúrgicas fue de 356.5 pesos (sE, 2013), lo que en

\footnotetext{
${ }^{6}$ Zazueta y Geluda (1981: 93) reportan que en 1978 las ramas minera y metalúrgica-siderúrgica emplearon un total de 393,374 personas.

${ }^{7}$ Información obtenida por medio del sistema Infomex del gobierno federal (https://www. infomex.org.mx/).
} 
términos reales es 19 por ciento inferior que en $1978{ }^{8}$ Desde otro ángulo, si bien el actual salario promedio de los mineros mexicanos es 40 por ciento más que el promedio nacional, sólo equivale a menos de 10 por ciento del salario promedio de los mineros en Canadá. ${ }^{9}$

En suma, durante el periodo neoliberal las ganancias extraordinarias en el sector minero mexicano han quedado en las manos de los principales accionistas de grandes compañías nacionales y extranjeras, se ha aumentado el grado de explotación de los trabajadores y las contribuciones al erario han sido mínimas.

Por último, es importante señalar que 55 por ciento de la producción minera en México es de oro y plata, ${ }^{10}$ con limitadas aplicaciones industriales. Sólo 12 por ciento de la producción mundial de oro entre 2007 y 2011 fue consumida por el sector industrial; 55 por ciento se utilizó para producir joyería y ornamentos, y 33 por ciento restante tomó la forma de lingotes para servir como base material para la especulación financiera (World Gold Council, 2013b). En cuanto a la plata, con las crecientes aplicaciones en la rama electrónica (especialmente en la fabricación de monitores y de televisiones de pantalla plana), la industria consume un poco más de 50 por ciento de la producción mundial (GFMS, 2011). En todo caso, se puede afirmar que la minería en México destruye el medio ambiente y los medios de vida de los campesinos e indígenas en gran medida con el propósito de producir artículos de lujo y prestigio para los ricos y crear un refugio para el capital especulativo.

\footnotetext{
${ }^{8}$ Con base en los datos encontrados en Zazueta y Geluda (1981: 93), se calcula que en 1978 el salario promedio anual en el mismo sector era de 55,715 pesos nominales. En términos reales, usando las tasas de inflación del Banco de México (http://www.banxico.org.mx), esta cifra es equivalente a 423.3 pesos diarios en 2012.

${ }^{9}$ La Asociación Minera de Canadá calcula que el salario semanal promedio de los mineros canadienses en 2011 fue de 1436 dólares (Mining Association of Canada, 2012: 6).

${ }^{10}$ Cálculo propio basado en datos presentados por Camimex (2013).
} 


\section{COSTOS AMBIENTALES Y SOCIALES \\ DE LA MEGAMINERÍA TÓXICA}

Después de casi 500 años de explotaciones mineras capitalistas en América Latina, las compañías mineras tienen que explotar yacimientos de cada vez más baja ley, es decir, con sólo pequeñas cantidades de minerales dispersas por amplias formaciones rocosas. Para explotar estos yacimientos, se requiere desarrollar minas gigantescas, cada vez más a cielo abierto. De esta manera, la escala y el ritmo de las explotaciones mineras han crecido de manera espectacular durante el periodo neoliberal.

La primera gran mina a cielo abierto en México se creó en 1944 en Cananea para extraer cobre. Para finales del siglo $\mathrm{xx}$, hubo 1,846 grandes minas a cielo abierto en el país (Jiménez et al., 2006:12) y se han desarrollado muchas más desde entonces. Las bocas de las megaminas cubren hasta miles de hectáreas, con profundidades de más de un kilómetro. Destruyen por completo la tierra, vegetación y vida silvestre, no sólo en la boca de la mina, sino en los "terrenos», donde se amontonan los desechos sólidos que frecuentemente contienen pequeñas cantidades de metales pesados. Además, los procesos de lixiviación utilizan enormes cantidades de agua, a tal grado que frecuentemente privan a los agricultores locales del líquido vital que ellos requiren para el riego y emplean sustancias tóxicas, incluso el cianuro en el caso de oro y plata. Las presas de jales emiten estas sustancias al medio ambiente, ya sea de manera paulatina por medio del viento, la lluvia y la gravedad, o de repente por medio de los accidentes, que son frecuentes.

Ha habido cuando menos seis grandes derrames en el sector minero mexicano durante los últimos dos años. Aparte del que sucedió en Cananea el 6 de agosto de 2014, la prensa nacional ha registrado los siguientes: 1) el derrame que ocurrió en septiembre de 2012 en la mina Peña Colorada en la sierra de Manantlán, entre los estados de Colima y Jalisco; 2) la presa de jales que se rompió el 20 de enero de 2013 en la mina de oro y plata que pertenece a la compañía Mina de Bacís en el estado de Durango, lo que mató a cuatro personas y contaminó el río 
Remedios; 3) la pipa que se accidentó el 22 de agosto de 2013 en el camino a la mina Mulatos en Sonora derramó 16,000 litros de cianuro de sodio cerca del río Yaqui; 4) la presa de jales de la mina de oro que pertenece al Proyecto Magistral en Durango se desbordó el 14 de agosto de 2014 por las lluvias y depositó en un arroyo cercano aproximadamente 2,000 metros cúbicos de jales saturados con cianuro; y 5) el derrame que ocurrió el 17 de octubre de 2014 cuando se rompió el muro de contención de la presa de jales de la mina Dos Señores en el estado de Sinaloa liberó 1,800 toneladas de material tóxico a un arroyo que desemboca en el río Baluarte.

En este contexto, a todos nos afecta la minería. Sin embargo, no cabe duda de que a la gente que más le repercute es a los campesinos e indígenas cuyos territorios contienen yacimientos de minerales valiosos o que están ubicados cerca de ellos. Estos sectores de la población, generalmente los más pobres y marginados, sufren a manos del gran capital minero y de sus cómplices en el gobierno el despojo de tierras, recursos naturales, paisajes culturales y sitios sagrados. La megaminería tóxica pone en peligro la salud de los pobladores locales y destruye los medios de vida de los agricultores, impulsando así un proceso de proletarización. En términos popularizados por David Harvey (2003), se trata de acumulación por desposesión.

Desde un punto de vista etnográfico, los efectos sociales de la megaminería en México han sido bien resumidos por el antropólogo Claudio Garibay y sus colaboradores, quienes presentan un modelo explicativo basado en el concepto de reciprocidad negativa, definido como "la intención de tomar algo impunemente sin dar nada a cambio» (Garibay y Balzaretti, 2009: 92). Con base en sus investigaciones de campo sobre las minas Peñasquito en Zacatecas y Los Filos-Nukay en Guerrero, ambas minas de oro a cielo abierto que pertenecen a la compañía canadiense Goldcorp, Garibay y sus colaboradores revelan cómo dicha compañía abusa de las relaciones de poder asimétricas en sus negociaciones con los ejidos y las comunidades indígenas afectadas, recurriendo al engaño, la cooptación, la coerción y el fraude para obtener los contratos 
de renta de tierra que requiere para llevar a cabo sus proyectos de explotación. Por un lado, la compañía genera la ilusión de prosperidad y "desarrollo»y ofrece regalos, empleos y proyectos sociales; por otro, soborna a las autoridades locales, amenaza a los inconformes y esconde la verdadera magnitud de los efectos ambientales (Garibay y Balzaretti, 2009; Garibay et al., 2011).

Donde la resistencia ha emergido, la policía, los militares y los paramilitares casi invariablemente prestan sus servicios para intimidar y reprimir a los participantes. Sobre este punto, múltiples líderes de los movimientos antimineros han sido asesinados en México durante los últimos años, entre ellos Mariano Abarca Roblero, del Frente Cívico de Chicomuselo en Chiapas; Bernardo Vásquez Sánchez, de la Coordinadora en Defensa de los Recursos Naturales y Nuestra Madre Tierra del Valle de Ocotlán, Oaxaca; Ismael Solorio Urrutia, del Barzón en Chihuahua; y Nazario Aldama Villa y Aristeo Flores Rolón, miembros del Consejo de Mayores en la Sierra de Manantlán, Jalisco.

¿Y qué pasó con la responsabilidad social empresarial? La evidencia empírica sugiere que ésta es meramente una estrategia discursiva para facilitar la captura política de las comunidades afectadas y para legitimar las acciones de las compañías mineras frente a sus accionistas. Esta estrategia se respalda por presupuestos relativamente pequeños, inversiones en el ámbito local que son eficaces en términos de costos y beneficios, combinadas con una campaña mediática para presumir los proyectos de la responsabilidad social empresarial y la generación de trabajos. En la realidad, los grandes proyectos de minería generan relativamente pocos trabajos para los pobladores locales, quienes por lo general carecen de la capacitación necesaria para hacer los trabajos técnicos que pagan más. Generalmente, las empresas mineras contratan a la gente local para trabajar como peones durante la fase de construcción; son contados los que obtienen trabajos permanentes y con frecuencia son los que habían apoyado a la compañía minera durante las negociaciones en turno a la firma de un contrato de "ocupación temporal» de tierras. 
Algunos datos de la mina Peñasquito sirven de ilustración. Como relata Garibay et al. (2011), cuando Goldcorp llegó al valle de Mazapil en el estado de Zacatecas, prometió trabajos abundantes para la población local. Sin embargo, durante la fase de construcción, o sea el apogeo de la creación de empleos, cuando dicha minera canadiense presumía haber creado 8,000 empleos, sólo unos 70 jóvenes locales estaban trabajando en el proyecto, en su mayoría como peones, recibiendo un pago de 5,000 pesos mensuales en promedio. Al mismo tiempo, el proyecto destruyó los medios de vida para 2,000 personas en el valle de Mazapil. Los afectados han protestado, diciendo que fueron engañados, y con razón: con todo, los pagos de renta, los costos de reubicación, los regalos, los proyectos de la responsabilidad social empresarial y otras transferencias a los afectados sólo sumaron 0.02 por ciento de las ganancias netas proyectadas durante los 22 años de esperanza de vida de la mina. En 2009, después de llevar a cabo acciones directas, incluso el bloqueo de las entradas a la mina, los ejidatarios de Cedros y El Vergel lograron subir esta cifra a 0.17 por ciento.

Como estas cifras indican, bajo las condiciones que prevalecen en México en la actualidad, la megaminería crea pocos trabajos en el ámbito local, y las poblaciones afectadas reciben una porción minúscula de las ganancias extraordinarias de la industria minera. Frente a estas injusticias y en defensa de los territorios, las culturas, la salud y los medios de vida de las comunidades afectadas, los movimientos de resistencia han emergido a lo largo y ancho del país.

En una revisión de 30 conflictos ecoterritoriales de alto perfil en torno a la minería en México, se observa que en casi dos terceras partes el movimiento articula un contundente "no a la minería»; mientras que en los demás casos los activistas locales luchan por mayor indemnización, la mitigación de los efectos ambientales o el cumplimiento de acuerdos con la empresa (Tetreault, 2014). Más de 80 por ciento de los conflictos registrados giran en torno a proyectos llevados a cabo por empresas extranjeras (ibid.). Esto tiene que ver no sólo con los sentimientos antiimperialistas que ayudan a galvanizar los movimientos de resistencia, 
sino también con el hecho de que son las empresas extranjeras que están en la delantera de la exploración, impulsando así la ampliación de la frontera minera hacia las regiones aisladas y previamente inexploradas del país. Con frecuencia, se trata de las «regiones de refugio indígena» (Aguirre,1991), mismas que tienen altos niveles de diversidad cultural y biológica (Toledo, 2002) y una larga trayectoria de resistencia organizada.

En efecto, más de la mitad de los 30 conflictos ecoterritoriales de alto perfil en México afectan a grupos indígenas (Tetreault, 2014). Si bien la característica indígena no siempre se traduce en resistencia, lo cierto es que los pueblos originarios han sido la punta de lanza de los movimientos antimineros en México. Su discurso pone énfasis en lo sagrado de la madre tierra, lo que introduce un "lenguaje de valoración» inconmensurable con el análisis económico de costos y beneficios (Martínez, 2011). De acuerdo con Fuente y Barkin (2013), los lenguajes alternativos de valoración se construyen en las comunidades indígenas de Oaxaca con base en la institución de la «comunalidad».

\section{LA RECIENTE REFORMA REDISTRIBUTIVA}

Como parte de un esfuerzo más amplio de ganar legitimidad en el marco del "Pacto por México», el gobierno de Peña Nieto prometió expedir «una nueva Ley para la Explotación Minera que revise el esquema de concesiones y pagos de derechos federales vinculados a la producción», con el objeto de recaudar recursos "prioritariamente en beneficio directo de los municipios y comunidades donde se establezcan las explotaciones mineras». Este compromiso se convirtió en una propuesta para hacer cambios a la Ley Minera, misma que fue aprobada por la Cámara de Diputados el 23 de abril de 2013, para posteriormente ser pasada al Senado, donde se congeló. Por otra parte, la esencia de dicha propuesta fue retomada en una serie de modificaciones hechas a la LFD, publicada en el Diario Oficial de la Federación el 11 de diciembre de 2013 y nuevamente con más detalle el 11 de agosto de 2014. 
El meollo de esta reforma es cobrar a las empresas mineras una especie de regalía, para posteriormente invertir los recursos obtenidos en programas de desarrollo social y saneamiento ambiental en los municipios y los estados donde se realizan las actividades mineras en México. En la propuesta original de modificación a la Ley Minera se propuso cobrar 5 por ciento de las ganancias netas declaradas por las empresa mineras; esta cifra subió 7.5 por ciento en el llamado «derecho especial sobre la minería», incorporado en la nueva LFD. Además, se crearon dos «derechos» de segunda importancia: 1) el «derecho adicional», que consiste en un incremento de entre 50 y 100 por ciento del costo de las concesiones; un costo irrisorio, que va desde 5.91 pesos por hectárea semestralmente durante los dos primeros años de la concesión hasta 129.24 pesos por hectárea a partir del décimo primer año de vigencia; y 2) el "derecho extraordinario», que consiste en un impuesto de 0.5 por ciento de los ingresos derivados de la enajenación del oro, plata y platino.

Según el artículo 275 de la nueva LFD, 80 por ciento de los recursos recaudados por los tres derechos mencionados se destinarán al Fondo para el Desarrollo Regional Sustentable de Estados y Municipios Mineros (FDRSEMm). Este Fondo, a su vez, canalizará 62.5 por ciento de sus recursos a los municipios en los que tiene lugar la explotación y obtención de minerales y el restante 37.5 por ciento a la entidad federativa correspondiente. El artículo 271 de la LFD estipula que los recursos del fondo "deberán ser empleados en inversión física con impacto social, ambiental y de desarrollo urbano positivo», y ofrece ejemplos: centros escolares, calles, caminos locales, alumbrado público, rellenos sanitarios, plantas de tratamiento de agua, alcantarillado, manejo de residuos sólidos, reforestación y sistemas de trenes suburbanos. Para tomar decisiones sobre cómo emplear los recursos dentro de estos renglones, se conforma el Comité de Desarrollo Regional para las Zonas Mineras, presidido por el titular de la Secretaría de Desarrollo Agrario, Territorial y Urbano en el nivel federal e integrado por un representante del gobierno estatal, un representante del ayuntamiento en donde se reali- 
zan las actividades mineras, un representante de las comunidades agrarias e indígenas afectadas y un representante de las empresas mineras relevantes.

En este esquema la participación de los afectados por la minería se reduce a un voto minoritario sobre cómo gastar los recursos administrados por los gobiernos municipales y estatales. Aun la participación de estos niveles de gobierno se limita a escoger entre proyectos que pretenden tener un efecto social y ambiental y que buscan contribuir al desarrollo urbano. Los gobiernos subnacionales no tienen el derecho de ejercer controles fiscales propios sobre la actividad minera, ni controles regulatorios ambientales significativos; todo queda en las manos del gobierno federal. Desde otro ángulo, es irónico que se destaca la búsqueda del desarrollo urbano cuando la población más afectada es campesina e indígena. He aquí vestigios de la vieja teoría de la modernización, donde esas poblaciones tienen un destino, desaparecer.

Otra limitación de la propuesta de Peña Nieto es que no aborda la cuestión de seguridad en las minas, algo que despareció misteriosamente del «Pacto por México». Asimismo, no hay una propuesta para revertir la «flexibilidad» incorporada a la Ley Laboral en 2012, ni para aumentar el valor real de los salarios.

Yendo más al grano, las reformas en materia minera incorporadas a la LFD ignoran por completo las demandas de los movimientos socioambientales en torno a la megaminería, mismas que fueron articuladas en julio de 2013 en la "Propuesta de nueva ley minera desde los movimientos sociales». ${ }^{11}$ En esta propuesta hay dos demandas centrales: que las actividades mineras dejen de ser "preferentes» y que el consentimiento de las comunidades sea obligatorio. El gobierno de Peña Nieto ha hecho oídos sordos a estas demandas; mantiene el statu quo, donde el gobierno federal es el custodio de los recursos subterráneos, los puede entregar al capital privado de cualquier origen nacional por medio de conce-

11 „Propuesta de nueva ley minera desde los movimientos sociales», disponible en: http:// consultaprevia.org.mx/?page_id=202363. 
siones de 50 años prorrogables y las actividades mineras tienen prioridad sobre cualquier otra actividad productiva.

Esta orientación política choca con el convenio 169 de la Organización Internacional del Trabajo (оIт) y también con la Declaración de las Naciones Unidas sobre los Derechos de los Pueblos Indígenas (DNUDPI), ambos ratificados por el gobierno de México. Según la Declaración, el Estado tiene la obligación de obtener el «consentimiento libre, previo e informado» de los pueblos indígenas «antes de aprobar cualquier proyecto que afecte a sus tierras o territorios y otros recursos, particularmente en relación con el desarrollo, la utilización o la explotación de recursos minerales, hídricos o de otro tipo». En última instancia los movimientos en torno a la minería buscan extender el derecho al consentimiento, libre, previo e informado a todas las comunidades rurales, independientemente de si son indígenas o no.

\section{Alternativas. el CASO de CAPUlálpam}

Si la megaminería tóxica no conlleva al desarrollo local o nacional, entonces ¿Cuáles son las alternativas? Algunas ideas y experiencias prometedoras que han emergido, especialmente en las regiones predominantemente indígenas del sur del país, incluyen el manejo forestal comunitario, el ecoturismo comunitario, la agroecología, la soberanía alimentaria y el comercio justo. El potencial de algunas de estas alternativas se ilustra por el caso de Capulálpam, una comunidad zapoteca localizada en la Sierra Juárez de Oaxaca.

En los años setenta del siglo xix se estableció en el territorio de Capulálpam una mina subterránea de oro y plata llamada Natividad, originalmente de capital español, se explotó hasta 2006. Los años de bonanza fueron los cuarenta, cincuenta y parte de los sesenta del siglo $\mathrm{xx}$, cuando la mina creó hasta 800 empleos. En aquel tiempo, los mineros locales formaron las secciones 15, 138 y 139 de la SNTMMSRm y recibieron salarios que permitieron "un ingreso seguro para las familias» (Cosmes, 2003: 58). Muchos hombres jóvenes se murieron en la mina 
por accidentes y enfermedades, por lo tanto, los mineros indígenas de Capulálpam reprodujeron la leyenda del Catrín, dueño del mundo subterráneo que hace posible la extracción de metales preciosos a cambio de un tributo en la forma de vidas humanas (Aquino, s/f). En 1993, en el contexto de las reformas neoliberales llevadas a cabo por el gobierno de Salinas, los directivos de la Natividad rescindieron de manera unilateral los contratos colectivos, para posteriormente contratar a trabajadores individualmente. A partir de entonces la mina se encaminó hacia la decadencia. ${ }^{12}$

Por otra parte, durante el periodo de la industrialización por sustitución de importaciones, el territorio de Capulálpam estaba sujeta a un alto ritmo de explotación forestal. En 1954, el gobierno federal otorgó a la Fábrica de Papel Tuxtepec (Fapatux) una concesión de 25 años para explotar los bosques de la comunidad, sin buscar el consentimiento de la población local. Cuando esa concesión estaba a punto de terminar, Calpulálpam y otras comunidades indígenas de la misma región se organizaron para prevenir su prorrogación. Con este objetivo, crearon la Organización para la Defensa de los Recursos Naturales de la Sierra de Juárez (Odrenasij). Después de una batalla larga que incluía el bloqueo de caminos y otras formas de acción directa, la Organización puso fin al periodo de concesiones en el sector forestal, iniciando así una nueva etapa de manejo forestal comunitario que ha sido notablemente exitoso en términos sociales, ambientales y económicos (Bray y Merino, 2004).

Con base en esta experiencia, dos décadas más tarde los zapotecos de Capulálpam se organizaron para resistir los planes de ampliar y acelerar las actividades mineras en su territorio. Fue en 2002 cuando la compañía canadiense Continuum Resources compró la mina Natividad, además de 54,653 hectáreas de concesiones mineras en la misma región. La Secretaría de Economía ni siquiera informó a la comunidad sobre la

12 Según Bray y Merino (2004: 153), a principios del siglo xxI la mina Natividad sólo empleaba alrededor de 100 personas. Según Aquino (2011: 6), para ese entonces la mina había quedado "prácticamente sin actividad». 
transferencia de concesiones, violando así el convenio 169 de la oit y la DNUDPI. Asimismo, entre 2002 y 2006, Continuum invirtió alrededor de cinco millones de dólares en obras de exploración y rehabilitación de la mina (Aquino, s/f), sin notificar a la comunidad. Descubrió reservas de oro y plata que implicaban el desarrollo de una mina a cielo abierto en la microcuenca más importante de la comunidad; una zona montañosa relativamente bien conservada, con altos niveles de biodiversidad y con un valor simbólico cultural como sitio sagrado.

Cuando los pobladores de Capulálpam se enteraron de los planes de Continuum Resources, iniciaron un proceso de resistencia organizada, con base en el poder político y legal de la Asamblea General de comuneros y comuneras. Se documentaron diversas formas de destrucción ecológica causadas por las actividades mineras locales, entre las más graves la desaparición de manantiales y arroyos, y el derrame de jales contaminados con arsénico y plomo. Se creó el Comité por la Defensa de los Recursos Naturales de Capulálpam y se levantaron litigios ante diversas instancias gubernamentales, incluyendo la Procuraduría Federal de Protección al Ambiente (Profepa), para exigir la clausura de la mina y para demandar el resarcimiento de la destrucción ambiental causada por Continuum Resources. ${ }^{13}$ La primera acción legal se llevó a cabo en junio de 2005, cuando el comisariado de Bienes Comunales de Calpulálpam interpuso una denuncia al respecto.

Como relata Salvador Aquino, un líder e intelectual orgánico de Capulálpam, la Profepa era renuente a actuar a favor de la comunidad (Aquino, 2011). Sin embargo, la resistencia organizada ejerció varias formas de presión política, incluyendo una marcha en la ciudad de $\mathrm{Oa}$ xaca, además de construir redes de solidaridad. Finalmente, la Profepa se vio obligado a clausurar la Natividad de manera temporal en octubre de 2006, después de haber realizado una inspección ambiental para verificar las afectaciones denunciadas.

${ }^{13}$ Las demandas de la comunidad están bien resumidas en el Punto de Acuerdo aprobado por el Senado de la República el 24 de agosto de 2011, disponible en: http://www.remamx.org/ capulalpam-mineria-y-punto-de-acuerdo-en-el-senado/. 
Cabe recalcar la importancia de la comunalidad en esta victoria (Fuente y Barkin, 2013). Capulálpam es una de las múltiples comunidades indígenas en el estado de Oaxaca gobernadas por los usos y costumbres. En este esquema, la Asamblea General es el órgano máximo y sirve como espacio para practicar la democracia directa; las autoridades se eligen no mediante el sistema de partidos políticos que predomina en la gran mayoría de los municipios del país, sino por medio de asambleas comunitarias con sus propias reglas internas. El «sistema de cargos» confiere responsabilidad y prestigio a las personas escogidas para hacer un servicio comunitario con la capacidad de autoridad, incluso todas las familias de la comunidad deben participar en los trabajos colectivos llamados tequios. El alto grado de organización comunitaria y de autonomía política ha sido clave en el éxito de la lucha social en Capulálpam, además de la solidaridad que se derive de la identidad indígena (Aquino, $\mathrm{s} / \mathrm{f}$ ).

En febrero de 2008, Capulálpam se incorporó en el padrón de los «pueblos mágicos» de México para promover el ecoturismo en el ámbito local. En el marco político de los usos y costumbres, se creó una cooperativa para gestionar el turismo y socializar los beneficios. Este proyecto colectivo incluye cabañas construidas con materiales locales, tours y aventuras en la naturaleza, tales como el rapel y la exploración de cuevas. La arquitectura colonial y las vistas espectaculares en Capulálpam ayudan a atraer visitantes. Con el crecimiento del turismo, muchas familias locales han aprovechado la oportunidad para abrir restaurantes, cafés, tiendas y otras microempresas.

En la medida en que Capulálpam ha tenido éxito con el ecoturismo, éste fue nutrido por los aprendizajes derivados de su experiencia con el manejo forestal comunitario. Sobre esta historia, Bray y Merino (2004: 149-170) describen cómo la Unidad de Aprovechamiento Forestal, desde su creación en Capulálpam en 1984, ha contribuido al desarrollo comunitario vía la creación de empleos, la provisión de madera para construcciones de locales y la generación de ingresos públicos para el financiamiento de obras públicas. En Capulálpam el manejo forestal 
comunitario ha financiado múltiples proyectos locales, tales como la electrificación, agua entubada, alcantarillado, una biblioteca pública, un centro de turismo y dos clínicas de salud (una basada en la medicina tradicional). Por otra parte, la tala de árboles y las actividades que agregan valor a la madera en el aserradero de la comunidad se llevan a cabo de manera esporádica, de tal manera que la tasa de extracción se queda por debajo de la mitad de los volúmenes señalados en la concesión otorgada por la Semarnat, lo que refleja la prioridad de la comunidad de conservar los bosques (ibid.).

Además de lo ya mencionado, Capulálpam cuenta con una cantera pública, manejada por otra cooperativa, que también provee materiales para obras de construcción en el ámbito local. De manera complementaria, los zapotecos de Capulálpam todavía practican la agricultura a pequeña escala para el autoconsumo familiar y para el mercado local. Los miembros de la comunidad que fueron entrevistados en noviembre de 2013 señalaron que las alternativas mencionadas han creado múltiples oportunidades de empleo en la comunidad para los jóvenes, a tal grado que se ha puesto fin a las altas tasas de emigración que prevalecía durante la segunda mitad del siglo xx, lo que tiene que ver también con una reducción gradual en el tamaño promedio de las familias locales.

Debido al éxito de la lucha y de las alternativas en Capulálpam, la comunidad se ha convertido en un ejemplo de inspiración para los movimientos antimineros. Por esta razón, fue escogida para ser la sede del Tercer Foro Nacional Tejiendo la Resistencia en Defensa de Nuestros Territorios, llevado a cabo en mayo de 2011 con la participación de representantes de 59 comunidades indígenas en México. Asimismo, Capulálpam sirvió como sede para el foro "Sí a la vida, no a la minería», organizado por el Movimiento Mesoamericano contra el Modelo Extractivo (M4) para intercambiar aprendizajes e ideas sobre la defensa de los territorios, la resistencia colectiva y la construcción de alternativas, entre el 17 y el 20 de enero de 2013. 


\section{CONCLUSIONES}

Las políticas de privatización, liberalización y desregulación han creado una situación en donde un número reducido de grandes compañías nacionales y trasnacionales controlan la producción y beneficio de los metales y minerales en México. Estas compañías operan en un marco institucional que les permite acaparar la renta derivada del control monopólico de las reservas minerales, y gracias a las políticas laborales vigentes, pueden explotar en México una fuerza de trabajo barata y flexible. Las políticas públicas neoliberales animan a estas compañías a desarrollar grandes minas a cielo abierto que emplean sustancias tóxicas y consumen enormes cantidades de agua. Estos proyectos destruyen los territorios, recursos naturales y paisajes que sostienen la salud, los medios de vida y las cosmovisiones de los campesinos e indígenas.

Hasta fechas recientes, el sector minero mexicano ha contribuido relativamente poco al erario pues como hemos visto, los impuestos bajos forman parte integral de la estrategia neoliberal para atraer inversiones privadas y extranjeras. Queda por ver cuántos ingresos públicos generan los derechos «especial, adicional y extraordinario» que se incorporaron en la nueva LFD. Los precios internacionales de los minerales y metales han disminuido desde 2012 y las inversiones en el sector minero mexicano cayeron 18 por ciento en 2013, con respecto al año anterior (Camimex, 2014: 10). En todo caso, la reforma se limita a recaudar un especie de regalía para posteriormente repartirla entre los gobiernos de los estados y municipios con actividades mineras. De esta manera, no es difícil ver que su propósito político es cooptar a los gobiernos locales y dividir los movimientos de resistencia, en un esfuerzo por consolidar el modelo extractivo minero.

$\mathrm{Al}$ insistir en que la minería sea preferente sobre cualquier otra actividad productiva, la reforma sólo aborda de manera parcial el tema de la distribución, dejando a un lado las demandas de los movimientos antimineros en torno a la participación y el reconocimiento político (Schlosberg, 2007). En el centro de estas demandas, se exige el respeto 
al derecho de los pueblos afectados a rechazar los proyectos mineros para seguir caminos alternativos al desarrollo. Además, las viejas demandas de los mineros en torno a los salarios dignos, la seguridad en el sitio de trabajo, la autonomía sindical y los términos de inclusión en los contratos colectivos siguen vigentes.

Desde otro ángulo, la limitada reforma redistributiva incorporada a la LFD se basa en una interpretación light del concepto de sustentabilidad, donde se supone que la destrucción del «capital natural» puede ser compensada a largo plazo por inversiones en la formación del «capital humano». En esta visión, el desarrollo local en las regiones mineras se convierte en una cuestión de ayudar a los afectados a cortar lazos con la tierra e insertarse en los mercados laborales en otros sectores de la economía, caracterizados por altos niveles de informalidad (más de 60 por ciento en México), salarios deprimidos y flexibilidad. Como parte de esta transición, se espera que una parte de la población desplazada por la megaminería encuentre trabajos en las minas, en su mayoría durante la fase de construcción. Cabe señalar también que, en la medida en que las empresas mineras ofrecen estos trabajos a los pobladores locales, se hace en el marco filantrópico de la responsabilidad social empresarial.

Las alternativas asociadas con los movimientos anti-mineros - tales como las que se practican en Capulálpam - son mucho más sustentables a largo plazo en términos ecológicos, sociales, económicos y culturales, ya que se prestan a la conservación de la diversidad biocultural. En vez de sacrificar territorios para generar ganancias para el gran capital minero, las alternativas como el manejo forestal comunitario y el ecoturismo comunitario proveen ingresos ampliamente distribuidos entre la población local, sin destruir la naturaleza. Estas alternativas y otras se basan en la condición imprescindible de proteger los ecosistemas locales y paisajes culturales, lo cual es la condición sine qua non de la "sustentabilidad fuerte».

Para generalizar y hacer más viables estas alternativas, se requiere fortalecer la lucha en todos los niveles. La idea de que podemos cambiar 
el mundo sin tomar el poder (Holloway, 2002) es contraproducente en tanto conduce a acciones individuales o colectivas limitadas en el nivel local. Los movimientos antimineros tienen que unir fuerzas con otros movimientos sociales izquierdistas para ganar control del aparato estatal y para transformarlo radicalmente. Las luchas por la autonomía en los ámbitos individual, familiar y comunitario tienen que ser complementadas por luchas en los ámbitos nacional e internacional. De otro modo, los movimientos sociales tienen que enfocar demasiada energía en apagar incendios y en defender los bienes comunes de un capitalismo rapaz que cuenta con el apoyo del Estado neoliberal.

Ahora bien, conquistar el Estado no necesariamente se traduce en el fin de la megaminería tóxica, tal como las experiencias recientes en Bolivia y Ecuador demuestran. Un último análisis: el desarrollo humano tiene que reflejar una racionalidad ecológica y social que implica una forma de socialismo, autonomía indígena y la desvaloración del oro y la plata. Seguramente hay mejores maneras de demostrar y simbolizar el amor entre una pareja que con un anillo de oro sangriento y ecológicamente destructivo.

\section{REFERENCIAS}

Aguirre Beltrán, Gonzalo (1991), Obra Antropológica IX. Regiones de Refugio: El desarrollo de la comunidad y el proceso dominical en mestizo América, México, Fondo de Cultura Económica.

Aquino, Salvador (2011), «La lucha por el control del territorio en Capulálpam. Diferentes maneras acerca de la comprensión del subsuelo, el oro, la plata, la ley y el capital», https://www.yumpu.com/es/document/view/14834508/ la-lucha-por-el-control-del-territorio-en-capulalpam-diferentes- (consultado el 25 de enero de 2014).

(s/f), «Ni oro, ni plata, ni dinero; lo que queremos es cuidar nuestros veneros», http://www.ibcperu.org/doc/isis/12599.pdf (consultado el 12 de marzo de 2014). 
Auditoría Superior de la Federación (asf) (2012), Informe del Resultado de la Fiscalización Superior de la Cuenta Pública 2010, http://www.asf.gob.mx/ Trans/Informes/IR2010i/Grupos/Desarrollo_Economico/2010_0809_a. pdf (consultado el 25 de mayo de 2012).

Bray, David y Leticia Merino (2004), La experiencia de las comunidades forestales en México, México, Instituto Nacional de Ecología.

Burnes Ortiz, Arturo (2006), El drama de la minería mexicana. Del pacto colonial a la globalización contemporánea, Zacatecas, Universidad Autónoma de Zacatecas.

Cámara Minera de México (Camimex) (2013), Informe Anual 2013, México, Camimex.

(2014), Informe Anual 2014, México, Camimex.

Coll Hurtado, Atlántida, María Teresa Sánchez-Salazar y Josefina Morales (2002), La minería en México, México, Instituto de Geografía de la UnAM.

Cosmes Belmonte, Mario (2003), Capulálpam de Méndez, México, Cámara de Diputados.

Delgado Wise, Raúl y Rubén Del Pozo (2002), Minería, Estado y gran capital en México. México, Centro de Investigaciones Interdisciplinarias en Ciencias y Humanidades, UnAm.

Denault, Alain y William Sacher (2012), Imperial Canada Inc. Legal Haven of Choice for the World's Mining Industries, Vancouver, Talon Books.

Fuente, Mario Enrique y David Barkin (2013), «Mining as a Development Factor in The Sierra Juárez in Oaxaca: An Ethical Evaluation», Problemas del Desarrollo, vol. 44, núm. 172.

Garibay, Claudio, Andrés Boni, Francisco Panico, Pedro Urquijo y Dan Klooster (2011), «Unequal Partners, Unequal Exchange: Goldcorp, the Mexican State, and Campesino Dispossession at the Peñasquito Goldmine», Journal of Latin American Geography, vol. 10, núm. 2, pp. 153-176.

y Alejandra Balzaretti Camacho (2009), «Goldcorp y la reciprocidad negativa en el paisaje minero de Mezcala, Guerrero», Desacatos, vol. 30, pp. 91-110.

GFMs (2011), The Future of Silver Industrial Demand, https://www.silverinstitute. org/site/wp-content/uploads/2011/07/futuresilverindustrialdemand.pdf (consultado el 12 de marzo de 2014).

Gordon, Todd (2010), Imperialist Canada, Winnipeg, Arbeiter Ring Publishing. 
Gudynas, Eduardo (2010), «El nuevo extractivismo del siglo xxi. Diez tesis sobre el extractivismo bajo el progresismo sudamericano actual», Memoria, núm. 242/243, pp. 12-17 / 24-30.

Harvey, David (2003), The New Imperialism, Nueva York, Oxford University Press.

Holloway, John (2002), Change the World without Taking Power, Londres, Pluto Press.

Jiménez, Carolina, Pilar Huante y Emmanuel Rincón (2006), Restauración de minas superficiales en México, México, Semarnat.

Martínez Alier, Joan (2011), El ecologismo de los pobres. Conflictos ambientales y lenguajes de valoración, Barcelona, Icaria.

Mining Association of Canada (2012), Facts and Figures of the Canadian Mining Industria 2012, en http://www.mining.ca/www/media_lib/MAC_Documents/Publications/2013/Facts\%20and\%20Figures/FactsandFigures2012Eng.pdf (consultado el 26 de noviembre de 2013).

Sariego, Juan Luis, Luis Reygadas, Miguel Ángel Gómez y Javier Farrera (1988), La industria paraestatal en Mexico: El estado y la minería mexicana. Política, trabajo y sociedad durante el siglo Xx, México, Fondo de Cultura Económica.

(2009), «De minas, mineros, territorios y protestas sociales en México: los nuevos retos de la globalización», Cabiers des Amériques Latines, núm. 6061, pp. 173-191.

Schlosberg, David (2007), Defining Environmental Justice. Theories, Movements, and Nature, Oxford, Oxford University Press.

Secretaría de Economía (se) (2012), Anuario estadístico de la minería mexicana, ampliada 2011, México, Coordinación General de Minería.

(2013), Reporte de coyuntura de la minería nacional, año 7, núm. 72, http:// www.economia.gob.mx/files/comunidad_negocios/industria_comercio/informacionSectorial/minero/reporte_de_coyuntura_mineria_nacional_0713.pdf (consultado el 25 de noviembre de 2013).

Tetreault, Darcy (2008), "Escuelas de pensamiento ecológico en las ciencias sociales», Estudios Sociales, vol. 16, núm. 32, pp. 227-263.

(2013), «La lucha en torno a la minería en Manantlán», Sociedad y Ambiente, vol. 1, núm. 2, pp. 47-74.

(2014), «Resistance and Reform in Mexico's Mining Sector», en James Petras y Henry Veltmeyer (eds.), Extractive Imperialism in the Americas. Capitalism's New Frontier, Leiden / Boston, Brill, pp. 194-233. 
Toledo, Víctor (2002), «Biodiversidad y pueblos indios», Biodiversitas, núm. 43, pp. 1-8.

World Gold Council (2013b), «Demand and Supply Statistics», en http:// www.gold.org/investment/statistics/demand_and_supply_statistics/ (consultado el 15 de marzo de 2014).

Zazueta, César y Simón Geluda (1981), Población, planta industrial y sindicatos. Relaciones entre sindicalismo y mercado de trabajo en México, 1978, México, Secretaría del Trabajo y Previsión Social. 